\title{
EVOLUTION OF DURABILITY AND MECHANICAL PROPERTIES OF ORDINARY PORTLAND CEMENT CONCRETES IN SULPHATES ATTACK
}

\author{
Zaidi Narimane $^{1^{*}}$ - Zedira Hamma ${ }^{1}$ - J.P. Castro-Gomes ${ }^{2}-$ Bezzazi Boudjema $^{3}$ - Talah Aissa ${ }^{4}-$ \\ Benbouras Mohammed Amin ${ }^{1}$
}

${ }^{1}$ Department of Mechanical engineering, Sciences and technologies Faculty, University of Abbas Laghrour, 40004 Khenchela, Algeria

${ }^{2} \mathrm{C}-\mathrm{MADE}$, Centre of Materials and Building Technologies, Department of Civil Engineering and Architecture, University of Beira Interior, 6201-001 Covilhã, Portugal

${ }^{3}$ URMPE, Materials, Processes and Environment Research Unit, University of M'Hamed Bougara, 35005 Boumerdes, Algeria

${ }^{4}$ LBE, Built Environment Research Laboratory, University of Science and Technology, 16111 Algiers, Algeria

\begin{tabular}{l}
\hline ARTICLE INFO \\
\hline Article history: \\
Received: 5.12 .2018$. \\
Received in revised form: 30.1 .2019$. \\
Accepted: 30.12 .2019$. \\
\hline Keywords: \\
Durability \\
Mechanical properties \\
Concrete \\
Cement \\
Sulphate attack \\
\hline DOI: http://doi.org/10.30765/er.40.3.04
\end{tabular}

\section{Introduction}

The gypsum soils in Algeria occupy about 8.000 $\mathrm{Km} 2$, which presents $12.2 \%$ of the gypsum soils of the world [1]. Sulfate attack expansion is one of the main factors causing the deterioration of concrete structure mostly at sulfate-rich external environment. Sulphate attack is defined as a reaction between sulphate ions, which can be found in groundwater, seawater, soils, and wastewater [2,3], and hydration products of cement which produce ettringite, causing

\footnotetext{
* Corresponding author.

E-mail address: narimane.zaidi15@gmail.com
}

\begin{abstract}
:
Concrete in sulphates environments often undergoes significant alterations that often have significant adverse results on its engineering properties. However, the choice of cement type is a very important factor for concrete exposed in aggressive environment. This research presents the effect of two types of cement on the mechanical and microstructure properties of ordinary concretes exposed in aggressive solution dosed with $5 \%$ of gypsum $\left(\mathrm{Ca}_{2} \mathrm{SO}_{4} \cdot 2 \mathrm{H}_{2} \mathrm{O}\right)$. The tests studied in this experimental part were the compressive strength, flexural strength, thermogravimetry, mercury intrusion porosimetry and mass variations of the concrete. The results clearly show that the CEM I 42.5 is suitable for the formulation of concretes exposed to sulphate attack and their properties are better compared with the CEM II/A 42.5.
\end{abstract}

cracking, expansion, loss of strength and other damages. This reaction is a threat to concrete durability in an aggressive environment. The damage caused by sulfate attack attracted researchers over the years to the search of the degradation mechanism and methods to combat it.

During the design of a concrete structure, one of the most important properties to be considered is durability. To check the durability of cementitious materials, there is an important factor which is the presence of aggressive fluids and their transport [4]. Predictions of durability of the service life can only 
be established on the basis of characterization of properties of the concrete materials and the environment $[5,6]$. The resisting capacity of concrete material to sulphate attack depends essentially on the quality of its constituents, further the cement matrix. However, the sulphates react with the tricalcium aluminate $\left(\mathrm{C}_{3} \mathrm{~A}\right)$ hydrate of the hardened cement paste resulting in an ettringite which, in the presence of moisture, expands to occupy a greater volume within the concrete.

Previous studies have shown that CEM I 42.5 utilization enhances properties of concrete at longer ages. Khelifa [7] conducted microscopic examination on concrete based on CEMI 42.5 exposed to sulphate attack. He observed that this cement is sulphate resistant and that behaves without evidence of alteration. In addition, Brunetaud and al. [8] reported that concretes made using CEM I 42.5 remained nonsensitive to sulphate attack. This cement confirms that the negative effects of exposure to sulfates result from the interaction between sulfates and phases related to the type of cement. Similar findings were noted by Zaidi and al. [9] that the CEM I 42.5 based concrete present a good permeability performance in an aggressive environment at longer ages. This indicates that the hydrates of this cement fill perfectly the voids in the cementitious matrix. This action prevents the penetration of harmful elements into the concrete. Moreover, results obtained by Khelifa in his experimental study [7], state that the CEMII 42.5 based concrete undergoes degradation and damage in sulphate medium. Moreover, the literature [10-1112-13] recommend using cement with a low concentration of aluminates or mineral additions. After hydration of cement, the hardened cement paste would result in less tricalcium aluminate hydrate hence the aggressive sulphates have less chance to react harmfully [14].

These data indicate that the sulfate-attack mechanism is complicated, the cracking and expansion of Portland cement concrete under sulfate attack is due to the formation of ettringite and gypsum [15]. Ettringite was defined as the main crystalline phase in the inner zone when gypsum is very close to the surface of concrete [16].

This paper gives a part of study durability properties of ordinary concretes made with CEMI 42.5 and CEMII 42.5 cement exposing to sulphate solution $\left(\mathrm{CaSO}_{4}, 2 \mathrm{H} 2 \mathrm{O}\right)$. The investigation was performed by means of compressive strength, flexural strength, thermogravimetry, mercury intrusion porosimetry, and mass variation.
The aim of this research is to possibly substitute the cement used previously, CEMII 42.5, manufactured by the cement plant LAFARGE Algeria (Meftah) with the new cement manufactured by the group GICA (cement plant of Ain Touta), CEMI 42.5, alleged as equivalent to cement sulphate resistant (CRS) in the case of ordinary concretes exhibiting in the sulphate environment. After the study and experimentation, CEMI 42.5 cement gave better results (see results in the article), and it is proposed to substitute CEMII 42.5 cement in sulphate exposures.

\section{Experimental investigation}

\subsection{Materials}

In this study, ordinary concrete mixes were prepared using two types of cement, CPA-CEM I 42.5 and CPJ-CEM II 42.5. Chemical composition properties of the cement are shown in Table 1. Natural siliceous was used as fine aggregate, sand with a maximum size of 4 and the coarse aggregate was crushed limestone with a maximum size of 15 . The physical properties of aggregates are summarized in Table 2. In order to achieve proper workability, a superplasticizer was used as a high water reducer polyvalent. It is a new chlorine-based acrylic copolymer generation, dry extract $30 \%$ and $\mathrm{PH}=4.5$ 6.5. The superplasticizer dosage was $3.20 \mathrm{Kg} / \mathrm{m}^{3}$ used for all concrete formulations.

\subsection{Mixture proportions}

The method of concrete formulation was determined by the method Dreux Gorisse, by optimizing the maximum diameter of coarse aggregate [17]. The same grain size distribution was selected for the two types of cement (CEMI 42.5, CEMII 42.5). The two types of concrete were elaborated with a constant W/C ratio equal to 0.48 . The mixture proportions are given in Table 3 . The characterizations of both concretes in their fresh state are given in Table 4. After 24 hours, one half of the concrete samples were stored in a sulphate environment (5\% CaSO4) and the other, in tap water (reference medium) for 365 days at ambient temperature.

\section{Test specimens and procedures}

Compressive strength test 
The compressive loading tests on concretes according to EN 12390-4:2000 [18] were carried out on a compression testing machine of $3000 \mathrm{kN}$ capacity. The specimen used was $150 \mathrm{~mm}$ cube. specimens were tested immediately after taking the cubes from curing tank in wet condition. The apparatus used for this research was a TGA Q50 V6.5 Build 196, in the temperature range from 20 to 1,000 ${ }^{\circ} \mathrm{C}$ at a rate of $20^{\circ} \mathrm{C} / \mathrm{min}$ under helium atmosphere. Mercury Intrusion Porosimetry (MIP)

The testing of porosity and pore structure was performed by Mercury Intrusion Porosimetry (MIP) with an 'AutoPore IV 9500 V1.07' mercury intrusion porosimeter, a $228 \mathrm{MPa}$ mercury porosimeter covering the pore diameter range from approximately 360 to $0.005 \mu \mathrm{m}$. This test was carried out on small concrete pieces, weighing approximately $6 \mathrm{~g}$.

Mass variations

The specimens of concrete designed for this test were cubic $150 \mathrm{~mm}$.

Flexural strength test

Table 1. Chemical compositions of the cements
The flexural strength test on concrete corresponds to EN 12390-5:2000 [19]. The prismatic specimens (70 $\times 70 \times 280 \mathrm{~mm}$ ) were fabricated and tested in fourpoint flexure machine of $50 \mathrm{KN}$ capacity.

Thermogravimetry analysis TGA.

To determine the mass of the concrete' s specimens prior to storage, they are weighed right after demolding. The cubes are submerged in both medium and weighed every three months for 365 days. Before weighing, the specimens are cleaned 3 times with distilled water to remove the top layer of concrete. After half an hour, weighing is recorded using a 0.01 gr precision scale.

After determination of the concrete' mass of the cubes at all ages, mass variations of immersed specimens were calculated as per following equation:

$$
\text { Mass Variation }(\%)=\frac{m_{2}-m_{1}}{m_{1}} \cdot 100
$$

Where $m_{2}$ refers to the mass of the specimen at testing time, and $\mathrm{m}_{1}$ is the mass of the same specimen at the initial age.

\begin{tabular}{|l|c|c|c|c|c|c|c|c|c|c|c|c|}
\hline & $\mathrm{Al}_{2} \mathrm{O}_{3}$ & $\mathrm{CaO}$ & $\mathrm{SiO}_{2}$ & $\mathrm{Fe}_{2} \mathrm{O}_{3}$ & $\mathrm{MgO}$ & $\mathrm{SO}_{3}$ & $\mathrm{~K}_{2} \mathrm{O}$ & $\mathrm{Na}_{2} \mathrm{O}$ & $\mathrm{Cl}$ & $\mathrm{LCL}$ & $\mathrm{PF}$ & $\mathrm{H}$ \\
\hline CEM I & 7.67 & 64.83 & 20.94 & 4.31 & 1.91 & 2.18 & 0.66 & 0.33 & 0.04 & 0.76 & 4.79 & 0.6 \\
\hline CEM II & 4.99 & 61.80 & 18.20 & 2.78 & 1.65 & 2.03 & 0.68 & 0.39 & 0.02 & 0.92 & 9.01 & 0.4 \\
\hline
\end{tabular}

Table 2. Physical properties of fine and coarse aggregates

\begin{tabular}{|c|c|c|c|c|c|}
\hline \multirow[t]{2}{*}{ Properties } & \multicolumn{4}{|c|}{ Aggregates used } & \multirow{2}{*}{ Standard method } \\
\hline & $8 / 15$ & $3 / 8$ & $0 / 4$ & $0 / 1$ & \\
\hline $\begin{array}{lll}\begin{array}{l}\text { Specific } \\
\left(\mathrm{g} / \mathrm{cm}^{3}\right)\end{array} & \text { gravity } & \text { (apparent) }\end{array}$ & 2.81 & 2.84 & 2.76 & 2.66 & $\begin{array}{l}\text { P } 18-558 \\
\text { P } 18-559\end{array}$ \\
\hline Specific gravity (dry) $\left(\mathrm{g} / \mathrm{cm}^{3}\right)$ & 1.52 & 1.46 & 1.44 & 1.46 & EN 1097-6 \\
\hline Absorption (\%) & 1.14 & 1.47 & 0.39 & 0.22 & $\begin{array}{l}\text { EN 1097-6 } \\
\text { P } 18-554\end{array}$ \\
\hline Water content $(\%)$ & 0.00 & 0.00 & 1.11 & 0.30 & $\begin{array}{l}\text { P } 18-554 \\
\text { P } 18-555\end{array}$ \\
\hline Porosity (\%) & 2.83 & 3.35 & - & - & P 18-554 \\
\hline Surface Cleanliness (\%) & 1.0 & 1.9 & - & - & P $18-591$ \\
\hline Kurtosis & 8.24 & 10.03 & & & NF EN 933-3/A1 \\
\hline Los Angeles (\%) & 20.82 & 24.48 & - & - & $\begin{array}{l}\text { NF EN 1097-2 } \\
\text { P } 18-573\end{array}$ \\
\hline Sand Equivalent (\%) & - & - & 63.56 & 74.35 & NF EN 933-8 \\
\hline The methylene blue value & - & - & 0.33 & 0.50 & NF EN 933-9 \\
\hline Micro-deval (A) (\%) & 18.2 & 18.5 & - & - & P 18-572 NF EN 1097-1 \\
\hline
\end{tabular}


Table 3. Concrete constituents and mix proportions

\begin{tabular}{|c|c|c|c|c|c|c|}
\hline $\begin{array}{c}\text { Water } \\
(\mathrm{L})\end{array}$ & $\begin{array}{c}\text { Cement content } \\
\mathrm{Kg} / \mathrm{m}^{3}\end{array}$ & $\begin{array}{c}\text { Sand 0/1 } \\
\mathrm{Kg} / \mathrm{m}^{3}\end{array}$ & $\begin{array}{c}\text { Sand 0/4 } \\
\mathrm{Kg} / \mathrm{m}^{3}\end{array}$ & $\begin{array}{c}\text { Gravel 3/8 } \\
\mathrm{Kg} / \mathrm{m}^{3}\end{array}$ & $\begin{array}{c}\text { Gravel 8/15 } \\
\mathrm{Kg} / \mathrm{m}^{3}\end{array}$ & $\begin{array}{c}\text { Super-plasticizer } \\
\mathrm{Kg} / \mathrm{m}^{3}\end{array}$ \\
\hline 209.97 & 400 & 184.37 & 621.13 & 279.74 & 666.88 & 3.20 \\
\hline
\end{tabular}

Table 4. Concrete properties (CEMIC: concrete based to CEMI cement, CEMIIC: concrete based to CEMIIC)

\begin{tabular}{|c|c|c|c|}
\hline & Slump $(\mathrm{cm})$ & Air Content $(\%)$ & Unit Weight $\left(\mathrm{Kg} / \mathrm{m}^{3}\right)$ \\
\hline CEMIC & 21 & 2.8 & 2390 \\
\hline CEMIIC & 22.5 & 3.2 & 2420 \\
\hline
\end{tabular}

\section{Results and discussion}

\subsection{Compressive and flexural Strengths}

The results of the compressive and flexural strength of concrete in both environments were calculated as the mean of the three measurements for all mixtures, and the measured values are presented in Figures 1,2 respectively. The compressive and flexural strength values and the standard deviation for each individual series of results are shown in Tables 5 and 6 (Each data point is the average for three specimens).

The results were in agreement with the previous studies [8]. While both types of cement are in the same class (42.5), the compressive strength of the concrete made with CEM I was higher than the compressive strength of the concrete made with CEM II.

Compressive strength increases gradually with the increase in the exposure time (until 270 days). This may be attributed to the continuous hydration of the anhydrous cement products, which decreases the volumes of micro-pores leading to a denser structure, which positively influences the mechanical strength, after that the strength starts to decrease.

In the case of the concrete exposed in tap water, high compressive strengths were achieved at the age of 365 days with an average of $67.4 \mathrm{MPa}$ for both concretes. On the other hand, for the concrete exposed in the aggressive environment, the highest level of long-term compressive strength (365days) was achieved for CEMIC (54 MPa) with 34\% difference to CEMIIC in sulphate environment.

As shown in Table 6, it can be observed that concretes based on CEMIC exhibited higher flexural strength compared to CEMIIC. From the results, it can be seen that CEMIC and CEMIIC cement concretes showed convergent flexural strengths at early ages, but remarkably divergent at later ages.

The improvement in flexural strength was more obvious at 270 days for CEMI concrete with $27 \%$ and $32 \%$ difference for both media ( $a$ and $b$ respectively). However, at 365 days it can be seen that the strength of concrete decreased for CEMIC levels up to $16 \%$, but is still superior to CEMIIC in sulfate medium with $29 \%$ difference. CEMIIC concretes had no change on the flexural strength of the concrete at 270 days and onwards.

Exhibition of the concrete specimens in sulfate medium caused a reduction in 365 day compressive and flexural strengths, in comparison to those of concrete specimens cured with water. However, the results were in the range as defined in the previous studies [20 and 21] where the formation of a sulfated hydrate leads to the creation of micro-cracks, a sign of a greater degradation of the material.

\subsection{Thermogravimetry analysis TGA}

Figures 3 and 4 shows TGA curves for both CEMIC and CEMIIC in tap and aggressive water respectively aged for 365 days. These curves provide basic information on the thermal behavior of the investigated concretes up to $1,000^{\circ} \mathrm{C}$.

In the results of the TGA test, whether in tap or aggressive water, every curve was divided into four zones of interpretation:

The first peak, delimited by 100 and $200^{\circ} \mathrm{C}$, for all concrete admixtures, is attributed to the loss of absorbed water by hydrated calcium silicate (C-S-H). The second zone covers the range between 350 and $450^{\circ} \mathrm{C}$, this part concerns just the CEMIC, which shows a relatively complicated behavior in aggressive water, a series of thermogravimetric 
bearings that it is difficult to identify. The literature results reported by $\mathrm{Xu}$ [22] ascribed these peaks to decomposition of hydrates $\mathrm{C}_{3} \mathrm{AH}_{2}$ at $250{ }^{\circ} \mathrm{C}$ [23], $\mathrm{C}_{4} \mathrm{AH}_{12}$ at $270{ }^{\circ} \mathrm{C}$ [24], and $\mathrm{C}_{3} \mathrm{AH}_{6}$ at $330{ }^{\circ} \mathrm{C}$ [23]. Around $420^{\circ} \mathrm{C}$, a relatively small total mass loss of $1.86 \%$ was found for CEMIC in tap water, an almost similar transformation was observed by Sha and al. [25] on cement paste. These authors attribute this peak to the change of crystalline state or the dehydration of a solid solution of $\mathrm{Fe}_{2} \mathrm{O}_{3}$.

The third zone, which ranges from 450 to $580^{\circ} \mathrm{C}$, is explained by the dehydration of calcium hydroxide $\mathrm{CaOH}_{2}$. The difference between mass loss in this stage appears with the exposition medium. Figure 3 showed just two important peaks for CEMIIC, at variance to Figure 4 which shows a suite of endothermic peaks for both concretes. This behavior may be attributable to the sulphate attack effect.

The last endotherm of around $700^{\circ} \mathrm{C}$, detected in all concrete admixtures, indicates the decarbonation of calcium carbonate in the hydrated compound.

The TGA curve in aggressive water CEMIC is associated with a total mass loss of $34.68 \%$ which is more than that of CEMII $30.48 \%$, but this is not the case for CEMI and CEMII in the tap water, which presented a total mass loss of $30.85 \%$ and $34.39 \%$ respectively. These basic TGA results emphasize important thermal stability for both concrete admixtures for possible high-temperature applications.

Table 5. Compressive strengths values of concrete at all tested ages

\begin{tabular}{|l|r|c|c|c|c|c|c|c|}
\hline & \multicolumn{7}{|c|}{ compressive strength } & \multirow{2}{*}{ SD } \\
\hline \multicolumn{1}{|c|}{ days } & 2 & 7 & 28 & 90 & 180 & 270 & 365 & \\
\hline CEMII-TW & 28.2 & 44.9 & 48.5 & 57.6 & 61.9 & 65.1 & 66.8 & 13.76922 \\
\hline CEMI-TW & 30.8 & 42.2 & 54.0 & 61.1 & 62.3 & 66.2 & 68.0 & 13.75619 \\
\hline CEMII-AW & 25.5 & 39.6 & 41.9 & 45.5 & 48.0 & 58.4 & 35.8 & 10.27619 \\
\hline CEMI-AW & 26.2 & 43.7 & 43.7 & 50.1 & 53.0 & 60.0 & 54.0 & 10.93631 \\
\hline
\end{tabular}

Table 6. Flexural strengths values of concrete at all tested ages

\begin{tabular}{|l|r|c|c|c|c|c|c|c|}
\hline & \multicolumn{7}{|c|}{ flexural strength } & \multirow{2}{*}{ SD } \\
\hline \multicolumn{1}{|c|}{ days } & 2 & 7 & 28 & 90 & 180 & 270 & 365 & \\
\hline CEMII-TW & 6.80 & 7.52 & 7.98 & 8.01 & 8.32 & 8.30 & 8.80 & 0.64458 \\
\hline CEMI-TW & 6.15 & 6.10 & 5.93 & 7.59 & 9.55 & 13.08 & 9.58 & 1.40291 \\
\hline CEMII-AW & 5.20 & 6.17 & 6.85 & 8.35 & 8.93 & 8.36 & 8.41 & 2.6341 \\
\hline CEMI-AW & 5.60 & 6.13 & 6.00 & 9.03 & 9.45 & 14 & 11.80 & 3.20677 \\
\hline
\end{tabular}

TW: tap water; AW : aggressive water ; SD : Standard Deviation
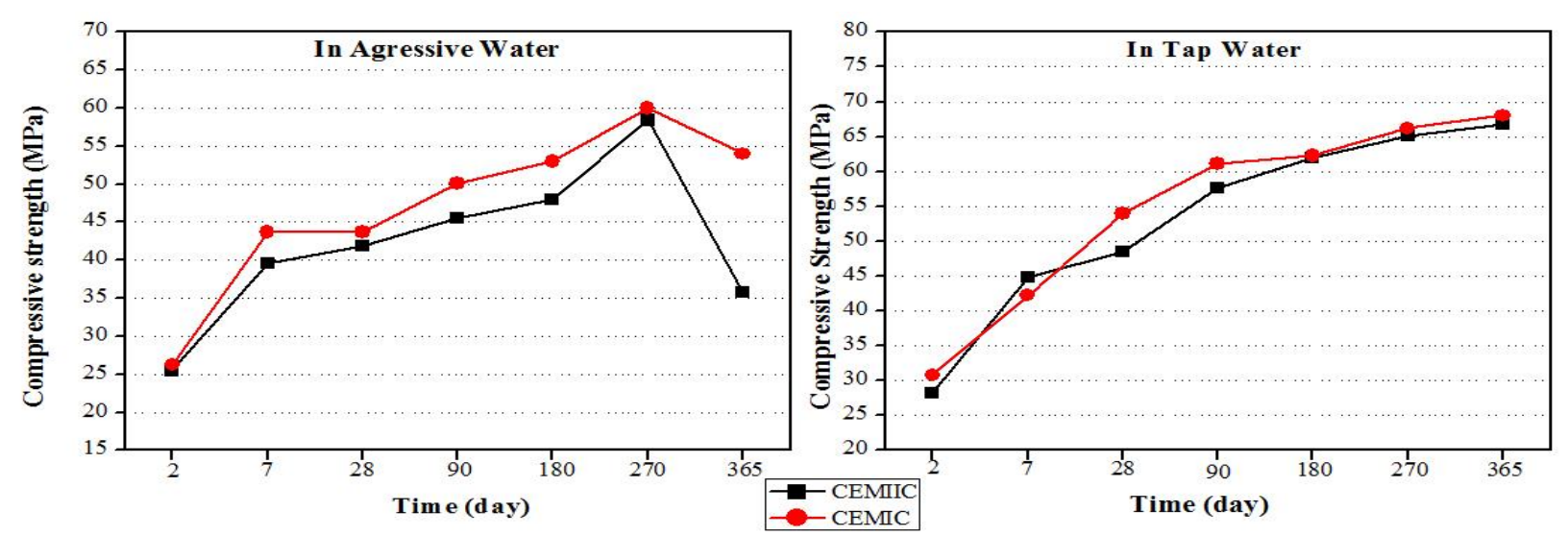

Figure 1. Evolution of compressive strengths 

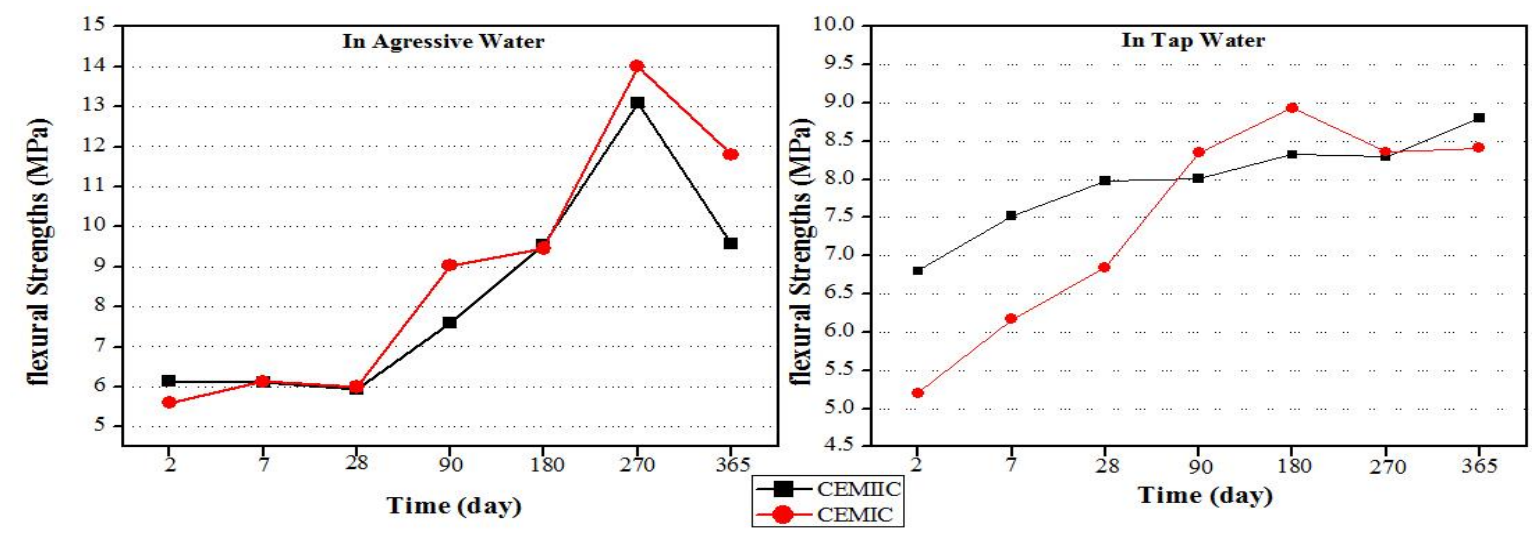

Figure 2. Evolution of flexural strengths

\subsection{Mercury Intrusion Porosimetry (MIP)}

Mercury intrusion porosimetry (MIP) analysis is widely used to evaluate total porosity and size distributions of pores in concretes. Researchers [26] classified the pores from 10 to $0.05 \mu \mathrm{m}$ as large capillary pores, from 0.05 to $0.01 \mu \mathrm{m}$ as medium capillary pores and $<0.01 \mu \mathrm{m}$ as gel pores.

Total porosity and porous distribution of concrete samples at 365 days are presented in figures 5 and 6 respectively.

Figure 5 shows the relationship between the cumulative pore volume and pore diameter in the range of 0.01 to $1000 \mu \mathrm{m}$. As can be seen, the lowest total porosity and the smallest diameter pore size, followed by CEMIC. The increase in capillary pore volume in CEMIIC can be attributed to a general microcracking of the cement matrix. The decrease in pore volume around $0.1 \mu \mathrm{m}$, which corresponds to the porosity of C-S-H, could mean that ettringite occupies a significant part of this porosity during sulphate attack [7].

It can also be clearly seen that there is not a difference in the total porosity for both concretes in tap water.

In figure 6, CEMIIC showed a higher volume of medium capillary pores and gel pores than CEMIC. The CEMIC pore size distributions presented may be associated with a sound material or at least slightly affected by the sulphate attack. Conversely to CEMIIC which presented peaks clearly more marked, the capillary pores are partially and completely filled with water and reduce as hydration continues. Capillary pores affect the strength and durability of concrete [27]. However, replacing CEM I with CEM II does translate into a shift to smaller pores.

It can be conclude that with the CEMIC, the total volume of the porosity and the refined pore size of concretes decrease, and the most probable pore diameters of concretes shift to smaller pores and fall in the range of less-harmful pore, which indicates that the use of CEMI 42.5 refines the pore structure of concretes in aggressive medium. MIP measurements confirmed the compressive and flexural strengths observations.

\subsection{Mass variations}

Figures 7 presents the results of the mass variations of different concrete cubes submerged in tap water and sulphate solution.

As shown, the mass of specimens submerged in the tap water increased gradually over time which probably corresponds to the hydration of the cement. Also, it can be seen that the specimens stored in sulphate solution showed much lower loss of mass. This increase of loss is due to the sulphate attack, which is formed as a result of the reaction between portlandite and calcium sulphate (CaSO4). The mass loss of concretes significantly increased with time when exposed to sulphate penetration [28].

Also, as it is illustrated in figure 7, mass reduction in the CEMIC was less than that of the CEMIIIC, these results confirm that the use of CEM I 42.5 cement prevents the formation of deleterious sulfate-related hydrated products [8].

The degradation of cementitious materials under these environmental conditions is represented by the total passage of solution of portlandite and by the progressive decalcification of HSCs, and in other words, of ettringite and monosulphoaluminate [29].

Figure 8 shows a visual inspection of CEMIC and CEMIIC $150 \mathrm{~mm}$ cube specimens submerged in sulphate solution after 365 days. This figure shows that apart from the white spots due to the deposition of $\mathrm{CaSO} 4$ on the surface of the specimens which are observed in the CEMIIC more than the CEMIC, no macroscopic indicator can detect a sulphate activity within the samples studied. 


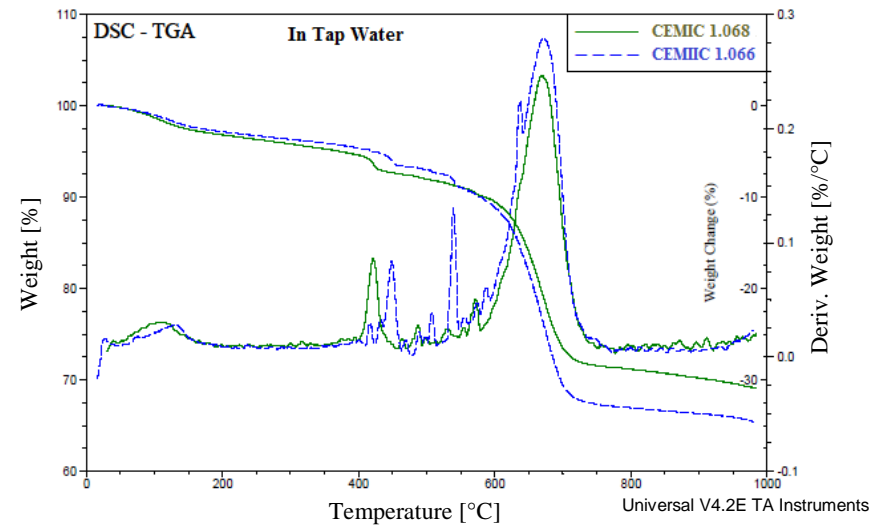

Figure 3.Thermogravimetric analysis output plot for samples in tap water
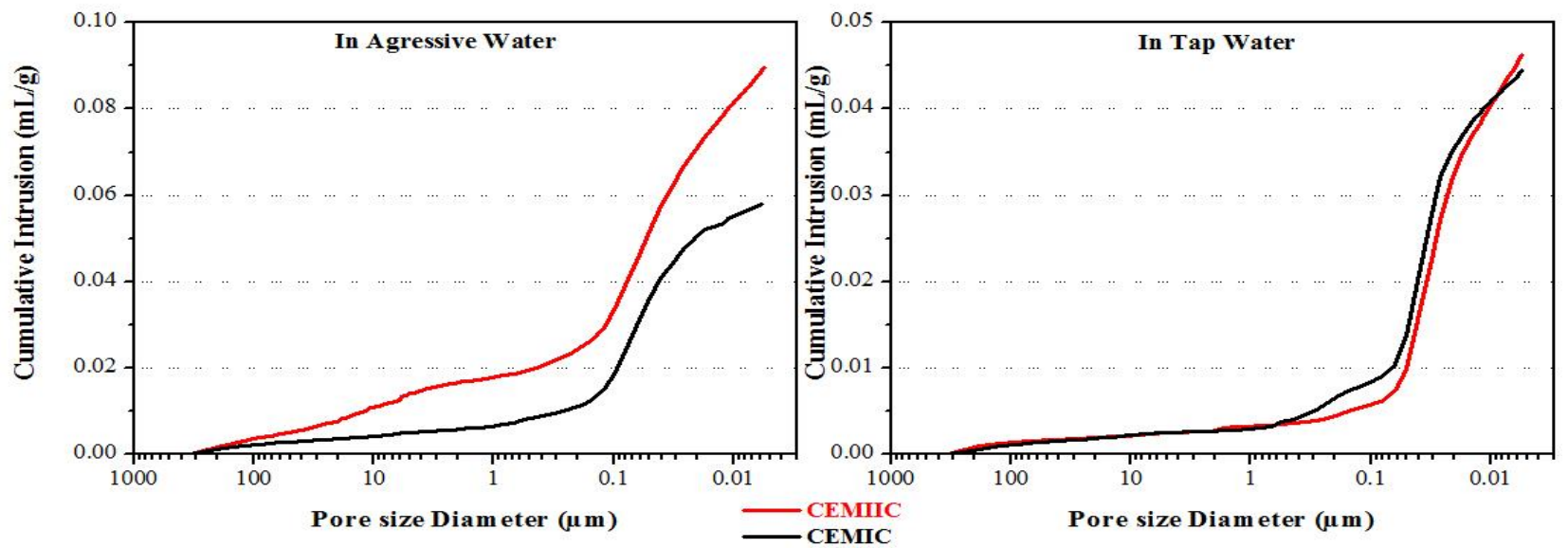

Figure 5. Total porosity of concretes in both medium at 365 days
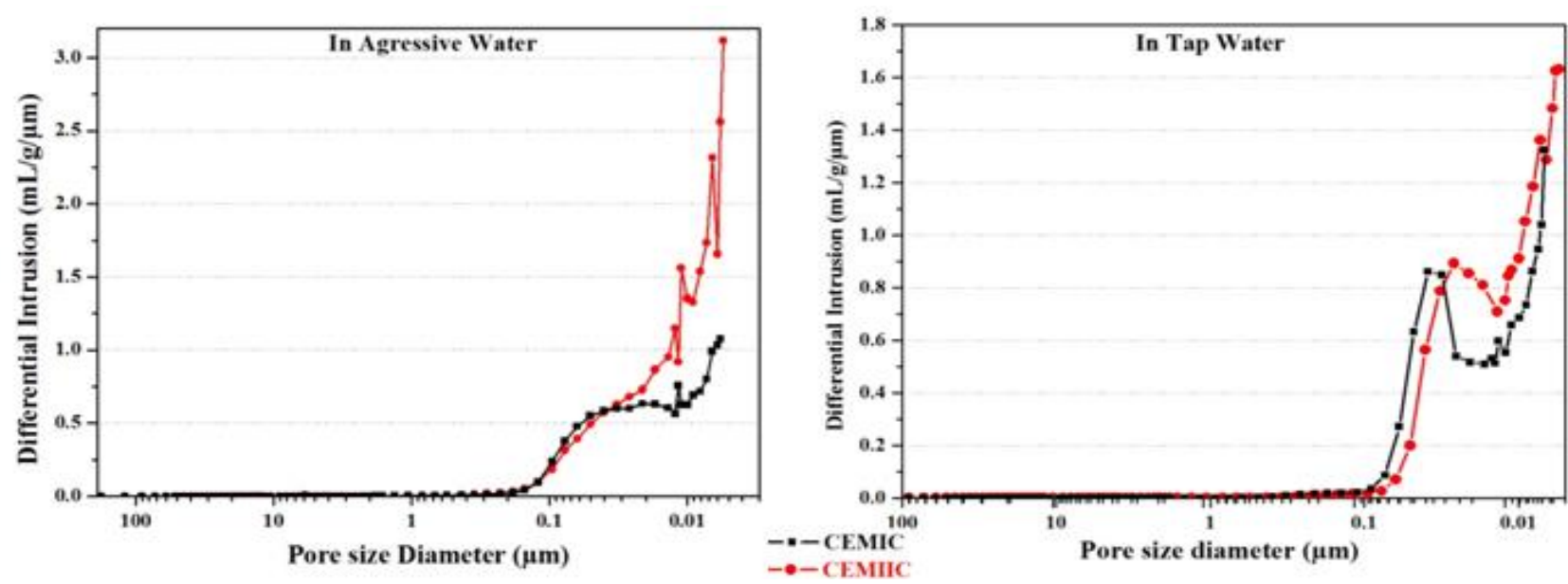

Figure 6. Pore size distribution of concretes in both medium at 365 days 

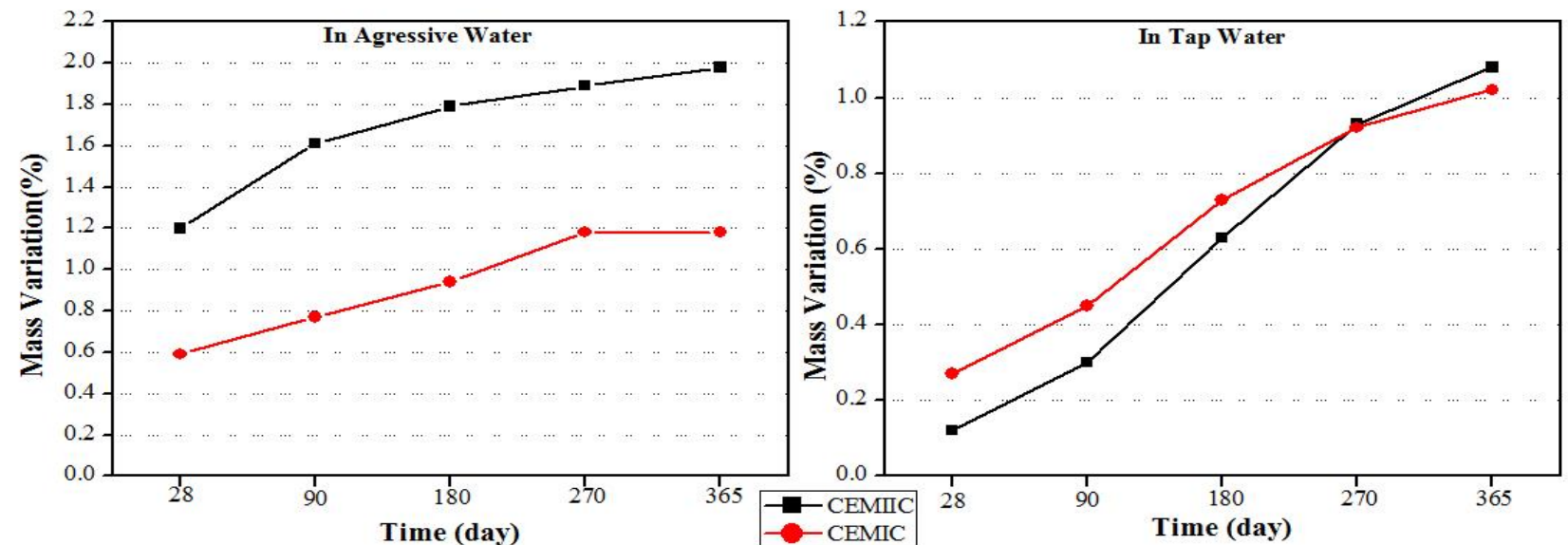

Figure 7. Mass variations of concretes in both medium at all tested ages

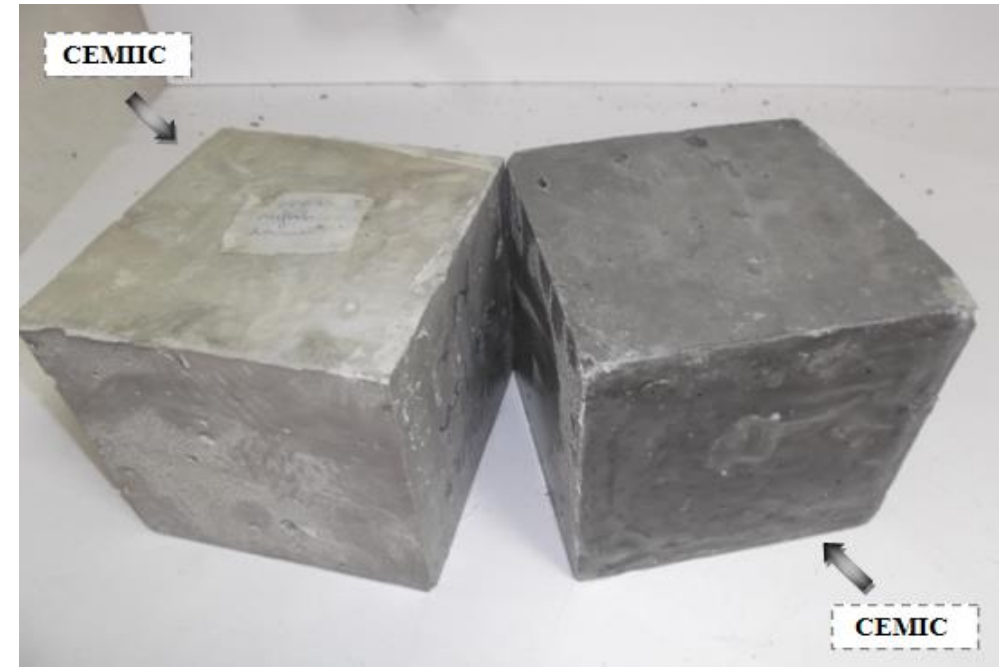

Figure 8. Visual inspection of CEMIC and CEMIIC $150 \mathrm{~mm}$ cubes after 365 days

\section{Conclusion}

The experimental results previously discussed lead to the following conclusions:

1 The behavior of exposed samples in tap water and sulphate environment is different; the referenced medium confirms that the negative effects of sulphate attack results from the interaction between sulfates and the type of cement.

2 The concrete with the lowest resistance to sulfates was that of CEM II 42.5 due to the decrease in compressive and flexural strength at 365 day; unlike CEMI 42.5 which presented good values of strength.
3 According to the TGA results, both concretes show important thermal stability, which allows them to be used for high-temperature applications.

4 The total pore volume of CEMIIC is higher than CEMIC. This is probably attributed to a general microcracking of the cement matrix. CEMI is less permeable, which confirms the compressive and flexural strengths observations.

5 CEMIC presented mass reduction less than that of the CEMIIC, which confirm that the use of this CEM I 42.5 cement prevents the formation of deleterious sulfate-related hydrated products.

6 No damage was observed in the specimens exposed to sulfate solution for 365 days. 
The various results confirmed that concretes made using CEM I 42.5 remained non-sensitive to sulphate attack.

\section{Acknowledgment}

This research was supported by Centre for Research and Development Lafarge HOLCIM, (Algiers, Algeria), and Centre of Materials and Building Technologies UBI (c-made), University of Beira Interior (Covilhà, Portugal). We are grateful to many staff members from these laboratories. We would like to thank the editor and the reviewers for their valuable comments which helped to improve quality of the paper.

\section{References}

[1] F.A.O.: Management of gypsiferous soils, FAO Soils $\mathrm{N}^{\circ} 62$, Rome, P81, 1990

[2] Biczók, I.: Concrete corrosion and concrete protection. New York, Chemical publishing, (1967).

[3] Figg J.: Field studies on sulfate attack on concrete. In: Marchand J., Skalny JP.: Sulfate Attack Mechanisms, Materials Science of Concrete, Westerbrook, Ohio: American Ceramic Society, (1999), 315-23.

[4] Hoseini, M., Bindiganavile, V., Banthia, N.: The effect of mechanical stress on permeability of concrete, a review, Cement and Concrete Research, 31 (2009), 213-20.

[5] ElDieb, A. S., Hooton, R. D.: Waterpermeability measurement of high performance concrete using a high-pressure triaxial cell. Cem Concr Res, 25(1995), 1199-208.

[6] Huseyin, Y., Halit, Y., Serdar, A.: Effects of cement type, water/cement ratio and cement content on sea water resistance of concrete, Build Environment 42 (2007), 1770-6.

[7] Khelifa, M. R.: Effet de l'attaque sulfatique externe sur la durabilité des bétons autoplaçants, Applied geology, Université d'Orléans; Université de Constantine,( 2010).

[8] Brunetaud, X., Khelifa, MR., Muzahi A. M.: Size effect of concrete samples on the kinetics of external sulfate attack, Cement \& Concrete Composites 34 (2012), 370-376.

[9] Zaidi, N., Zedira, H., Talah, A., Bezzazi, B.: Etude expérimentale de la perméabilité aux gaz d'un béton à base de ciment résistant aux sulfates dans un milieu agressif, 3ème Congrès
International sur la Technologie et la Durabilité du BétonCITEDUB3 Alger, (2016).

[10] Ganjian, E., Pouya, H.: Effect of magnesium and sulfate ions on durability of silica fume blended mixes exposed to the seawater tidal zone, Cement and Concrete Research, 35 (2005), 1332-43.

[11] Lee, S. T. H., Swamy, R.N.: Sulfate attack and role of silica fume in resisting strength loss, Cement Concrete Composite, 27 (2005), 65-76.

[12] Sezer, G., Ramyar, K., Karasu, B. A. B., Sezer, A.: Image analysis of sulfate attack on hardened cement past, Materials \& Design, 29 (2008), 224-31.

[13] Shannag, M. J., Hussein, A. S.: Sulfate resistance of high-performance concrete, Cement Concrete Composite, 25(2003), 363-9.

[14] Chemrouk, M.: The deteriorations of reinforced concrete and the option of high performances reinforced concrete, The 5th International Conference of Euro Asia Civil Engineering Forum (EACEF-5), Procedia Engineering 125 (2015) 713 - 724.

[15] Mehta, P.K.: Sulfate attack on concrete: separating myths from reality, Concrete International, 22 (2000), 57-61.

[16] Stroh, J., Schlegel, M. C., Irassar, E. F., Meng, B., Emmerling, F.: Applying high resolution SyXRD analysis on sulfate attacked concrete field samples, Cement Concrete Research 66 (2014) 19-26.

[17] Dreux G., Festa J.: Nouveaux Guide De Béton et De Ses Constituants, editions eyrolles, Paris 1998.

[18] European standard P 18-441, Part 4: Compressive strength -Specification for testing machines, testing hardened concrete.

[19] European standard P 18-433, Part 5: Flexural strength of test specimens, testing hardened concrete.

[20] Benabed B., Azzouz L, Damene Z.: Comportement mécanique et durabilité de mortiers a base du sable de dune, Colloque CMEDIMAT, Oran, Algeria, (2005).

[21] Turker F., and al.: Effects of magnesium sulfate concentration on the sulfate resistance of mortars with and without silica, Cement and Concrete Composite, Paris, (2003), 429-437.

[22] Xu, A.: Structure of hardened cement-fly ash systems and their related properties, Thèse de Doctorat de Chalmers University of Technology, Göteborg-Suède, (1992), 256. 
[23] Schwiete E.H., Ludwig U.: Crystal structure and properties of cement hydration products (hydrated calcium aluminates and ferrites), Proceeding of the 5th Int. Symposium on the Chemistry of Cement, Tokyo, 2(1968), 37-36.

[24] Sersale, R., Sabatelli, V., Valenti, G. L.: Influence of some retarders on the hydration, at early ages, of tricalcium aluminate, Proceeding of the 7th International Congress on the Chemistry of Cement, 4(1980), Paris, 546.

[25] Sha, W., O'Neill, E. A., Guo.: Differential scanning study of ordinary portland cement, Cement and Concrete Research, 29 (1999), 1487-1489.

[26] Zhang, M. H., Islam, J.: Use of nano-silica to reduce setting time and increase early strength of concretes with high volume fly ash or slag, Construction and Building Materials, 29 (2012), $573-80$.
[27] Faiz, U.A., Shaikh., Steve, W.M., Supit.: Compressive strength and durability properties of high volume fly ash (HVFA) concretes containing ultrafine fly ash (UFFA), Construction and Building Materials, 82 (2015), 192-205.

[28] El-Hachem, R., Rozière, E., Grondin, F., Loukili, A.: New procedure to investigate external sulphate attack on cementitious materials, Cement \& Concrete Composites 34 (2012) 357-364.

[29] Perlot, C., Verdier, J., Carcassès, M.: Influence of cement type on transport properties and chemical degradation: Application to nuclear waste storage, Materials and structures, 39 (2006), 511-23. 